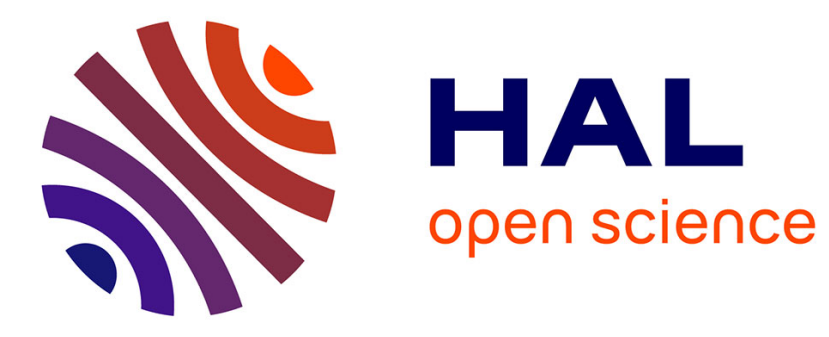

\title{
Propagation of vibrations due to a tramway line
}

Marc Maldonado, O. Chiello, Donatien Le Houedec

\section{- To cite this version:}

Marc Maldonado, O. Chiello, Donatien Le Houedec. Propagation of vibrations due to a tramway line. Burkhard Schulte-Werning, David Thompson, Pierre-Etienne Gautier, Carl Hanson, Brian Hemsworth, James Nelson, Tatsuo Maeda, Paul de Vos. Noise and Vibration Mitigation for Rail Transportation Systems, 99, Springer Verlag, pp.158-164, 2008, Notes on Numerical Fluid Mechanics and Multidisciplinary Design 978-3-540-74893-9. 10.1007/978-3-540-74893-9_22 . hal-01007536

\section{HAL Id: hal-01007536 https://hal.science/hal-01007536}

Submitted on 17 Nov 2017

HAL is a multi-disciplinary open access archive for the deposit and dissemination of scientific research documents, whether they are published or not. The documents may come from teaching and research institutions in France or abroad, or from public or private research centers.
L'archive ouverte pluridisciplinaire HAL, est destinée au dépôt et à la diffusion de documents scientifiques de niveau recherche, publiés ou non, émanant des établissements d'enseignement et de recherche français ou étrangers, des laboratoires publics ou privés. 


\title{
Propagation of Vibrations Due to a Tramway Line
}

\author{
M. Maldonado ${ }^{1}$, O. Chiello ${ }^{2}$, and D. Le Houédec ${ }^{1}$ \\ ${ }^{1}$ GeM Laboratory, Ecole centrale de Nantes, 1 rue de la Noë, 44321 Nantes Cedex 3, France \\ Tel.: +33 (0)2 4149 16 64; Fax: +33 (0)2 41491669 \\ marc.maldonado@ec-nantes. fr \\ ${ }^{2}$ INRETS, 25 av. F. Mitterrand, 69675 Bron Cedex, France \\ Tel.: +33 (0)4 721424 05; Fax: +33 (0)4 72376837 \\ olivier.chiello@inrets.fr
}

\begin{abstract}
Summary
Tramway traffic may produce vibrations propagating in soil leading to vibration annoyance for people living or working in neighbouring buildings. Thus vibration is an important parameter to be considered when planning new lines and dynamic performance evaluation of tramway tracks is necessary to validate or modify the existing means that reduce vibrations. This paper presents experimental and theoretical investigations of vibrations caused by tramway passages in Nantes, France. It focuses on the control of ground-borne vibrations for the whole system, taking into account important elements such as the dynamic vehicle characteristics, the track and the soil behaviour. A complete track-soil-ground model is proposed to predict ground-borne vibrations, so as to estimate a trouble gauge concerning - for example - the impact of a future tramway line.
\end{abstract}

\section{Introduction}

Nowadays, the tramway is more and more developed so as to reduce traffic jams in large cities. It offers a fast and alternative means of transport but nevertheless can produce new kinds of vibration (and sound) annoyance for people walking in the street or staying in buildings near the tramway line. The level of noise and vibration depends highly on the soil and track characteristics, and also on the vicinity of houses, buildings and in some cases on streets profile (narrow or wide). Within the frame of this problem, this proposal investigates only the vibration field with the objective to deduce the response of the track and of the surrounding soil, due to a tramway passage.

The modelling of ground-borne vibrations is a general subject that is widely dealt with in literature (see review in Lombaert et al. [1]). Difficulties arise when the whole structure (i.e. tramway, track and soil) has to be considered, therefore rarely is the complete vehicle-track-ground system taken into account. In the first part of the paper, the model proposed for the track and the coupling conditions with the ground is drawn from Sheng et al. [2]. These authors coupled a two-dimensional track model to a layered halfspace model of the soil, using the Haskell-Thomson transfer matrices approach. Here a semi-analytical model is adopted (firstly introduced by Jones [3]) to obtain the flexibility matrix of the layered soil in the wavenumber domain (extended model in [4]). In the second part of the paper, track and soil characteristics are fitted 
using both measurements, and manufacturer data. Then the tramway passage is calculated, using results from the first part concerning the point load solution. Hence, tramway dynamic load is implemented assuming that wheel-rail contact forces behave as uncorrelated fixed point loads. A comparison between calculations and measurements is finally made, in the particular case of a concrete slab track.

\section{Track-Soil-Ground Model}

\subsection{Receptance of the Ground}

The ground is modelled as a multilayered and semi-infinite medium (figure 1), each layer being elastic, homogeneous and isotropic. For each layer, Navier's dynamic equation and linear behaviour law between stresses and displacements are written. Next, the use of the double Fourier transform

$$
\bar{f}(\beta, \gamma, z)=\int_{-\infty-\infty}^{+\infty+\infty} f(x, y, z) \cdot e^{-i \cdot(\beta \cdot x+\gamma \cdot y)} \cdot d x d y
$$

provides the writing of the motion equation into the domain of the wave numbers $\beta$ in the $x$ direction and $\gamma$ in the $y$-direction. $x, y$ and $z$-directions correspond to the longitudinal (infinite) track direction, the transversal track direction, and the subsoil direction, respectively. Finally, it yields for each layer

$$
\begin{gathered}
\left\{\bar{u}^{*}(0), \bar{v}^{*}(0), \bar{w}^{*}(0), \bar{u}^{*}(h), \bar{v}^{*}(h), \bar{w}^{*}(h)\right\}^{T}=[T] \cdot\{\bar{A}, \bar{B}, \bar{C}, \bar{D}, \bar{E}, \bar{F}\}^{T}(2) \\
\left\{-\bar{\sigma}_{x z}^{*}(0),-\bar{\sigma}_{y z}^{*}(0),-\bar{\sigma}_{z z}^{*}(0),+\bar{\sigma}_{x z}^{*}(h),+\bar{\sigma}_{y z}^{*}(h),+\bar{\sigma}_{z z}^{*}(h)\right\}^{T}=[S]\left\{\{\bar{A}, \bar{B}, \bar{C}, \bar{D}, \bar{E}, \bar{F}\}^{T}\right.
\end{gathered}
$$

where $\bar{\sigma}_{x z}^{*}, \bar{\sigma}_{y z}^{*}, \bar{\sigma}_{z z}^{*}$ indicate the stresses, and $\bar{u}^{*}, \bar{v}^{*}$ and $\bar{w}^{*}$ the displacements. All these elements are defined in the wave number domain in the $x, y$ and $z$-direction respectively. The mark 0 corresponds to the top of the considered layer, and $h$ to its bottom. In the following, a bar above a variable denotes its representation in the wave number domain, therefore $\beta, \gamma$ are omitted. $[S]$ and $[T]$ are $6 \times 6$ matrices and $\bar{A}, \bar{B}, \bar{C}, \bar{D}, \bar{E}, \bar{F}$ are unknown constants. Thus, one obtains the following matrix equation (which eliminates constants)

$$
[S] .[T]^{-1} \cdot\left\{\bar{u}^{*}\right\}=\{\Sigma\}
$$

where $[S] .[T]^{-1}$ is the exact dynamic stiffness matrix of the layer derived in the transform domain, and its inverse is called the Fourier-transformed dynamic flexibility matrix of the layer. A dynamic stiffness matrix can also be derived for the halfspace. These matrices are then assembled to form a flexibility matrix representing the response at the surface of the whole ground. That is the reason for the minus or plus in the definition of displacement and stress matrices (equations (2)(3)) so that the 
stresses at the layer interfaces other than the top and bottom of the ground cancel (for more details see [5]).

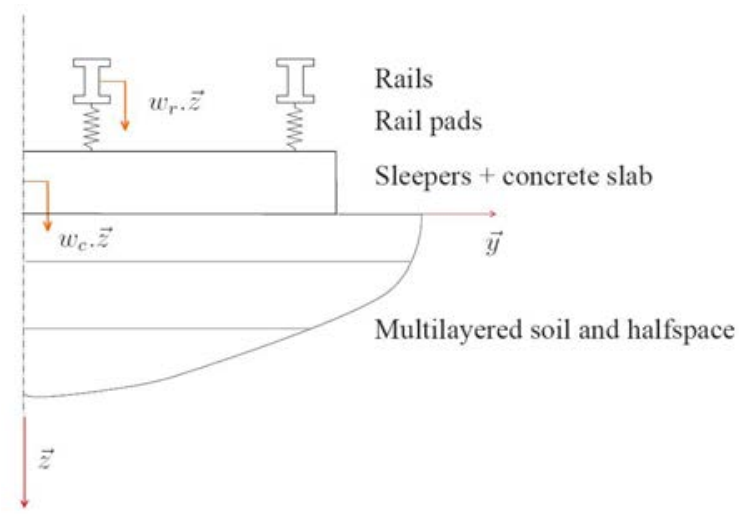

Fig. 1. Track-soil-ground model

The vertical direct receptance of the ground due to a surface harmonic load of wave number $\beta$ in the $x$-direction is given by [6]

$$
\bar{H}(\beta)=\frac{1}{\pi} \int_{0}^{+\infty} \bar{Q}_{33}(\beta, \gamma) \cdot \frac{\sin (\gamma \cdot b)}{\gamma \cdot b} d \gamma
$$

where $\bar{Q}_{33}$ is deduced from the flexibility matrix, $\gamma$ represents the wave number associated with $y$-direction, and $b$ is the half width of the track-soil interface. This receptance will be introduced in the track equations to obtain the coupled model.

\subsection{Coupled Model}

Rails and concrete slab are modelled by means of infinite Euler beams and rail pads by continuous spring elements (equivalent continuous track models provide a reliable prediction of track receptance, more details available in [7] and Cui et al. [8]). Damping is taken into account as hysteretic one. All equations are derived in the wave number domain, using a one dimensional Fourier transform. The receptance of the soil is then introduced to complete these equations providing the "stiffness" of the soil. Precisely, concrete slab vertical displacement equals subsoil vertical displacement for the whole concrete slab/subsoil interface in the $x$-direction, assuming that displacements are identical in the $y$-direction at the interface. Finally, coupled model equations can be written in the wave number domain as

$$
\left[\begin{array}{ccc}
A_{1} & A_{2} & 0 \\
A_{2} & A_{3} & 1 \\
0 & 1 & -\bar{H}(\beta)
\end{array}\right] \cdot\left\{\begin{array}{l}
\bar{w}_{r}^{*} \\
\bar{w}_{c}^{*} \\
\bar{F}_{c}^{*}
\end{array}\right\}=\left\{\begin{array}{l}
P^{*} \\
0 \\
0
\end{array}\right\}
$$


where

$$
\left\{\begin{array}{l}
A_{1}=-m_{r} \cdot \omega^{2}+k_{p} \cdot\left(1+i \cdot \eta_{p}\right)+E_{r} I_{r} \cdot\left(1+i \cdot \eta_{r}\right) \cdot \beta^{4} \\
A_{2}=-k_{p} \cdot\left(1+i \cdot \eta_{p}\right) \\
A_{3}=-m_{c} \cdot \omega^{2}+k_{p} \cdot\left(1+i \cdot \eta_{p}\right)+E_{c} I_{c} \cdot\left(1+i \cdot \eta_{c}\right) \cdot \beta^{4}
\end{array}\right.
$$

All these elements are considered per unit length of the track in the $x$-direction: $m_{r}$ or $m_{c}, E_{r} I_{r}$ or $E_{c} I_{c}$ and $\eta_{r}$ or $\eta_{c}$ are mass, bending stiffness and hysteretic damping ratio of the rail or concrete slab, respectively ; $k_{p}$ and $\eta_{p}$ are the stiffness and hysteretic damping ratio respectively, concerning the continuous rail pad element; the unknown quantities of equation (6) are $\bar{w}_{r}^{*}$ (rail center vertical displacement), $\bar{w}_{c}^{*}$ (concrete slab center vertical displacement) and $\bar{F}_{c}^{*}$ (force acting between the concrete slab and the soil), and $P^{*}$ stands for the one-dimensional Fourier transform of the point-force P. $\delta\left(x-x_{0}\right)$ acting on the rail at the point $x=x_{0}$. Finally equations are solved, first in the wavenumber domain and then the real displacements are obtained by means of inverse Fourier transforms (one or two dimensional, as concerning the track or the soil respectively).

\section{Comparison with Measurements}

The parametrical analysis mainly includes the tramway speed (from 20 to $50 \mathrm{~km}$ per hour), the tramway type (two manufacturers) and the track type (classical track, special track with softer rail pads, or lying on an elastic slab). In this paper, we only present results for a classical tramway track, without specific insulation. First, the soil is characterised by measurements using the Spectral Analysis of Surface Waves (S.A.S.W.). The objective is here to define shear moduli, layer thicknesses, scattering parameters and material damping. Secondly, the track receptance and the transfer functions between the track and the free field give information concerning the track parameters. Finally, measurements on the moving vehicle are used to obtain data relative to the real dynamic forces acted by the tramway on the rails. Besides, for each site, measurements were recorded to obtain an important data base concerning vibration levels induced by tramway passages, both on the rail and the ground surface.

\subsection{Soil Characteristics}

Soil is characterised by measurements using the usual two-stations S.A.S.W. test with hammer impacts. The phase of the cross-power spectrum of the two receiver responses is used to obtain the phase velocity (of Rayleigh waves) vs. frequency. Attention must be paid to the frequency range of acceptable data (near field and attenuation effects) [9]. An inversion algorithm using a least squares optimisation routine [10] is then implemented to obtain a layered soil which corresponds to the experimental dispersion curve. The inversion procedure only gives Young's moduli, so the material 
soil damping $\eta$ has to be chosen using a different method. Hence, the soil admittance is used to fit the hysteretic damping ratio for each layer. The results are presented in figure 2 (a). A good agreement is found for the comparison between the numerical and the experimental results.

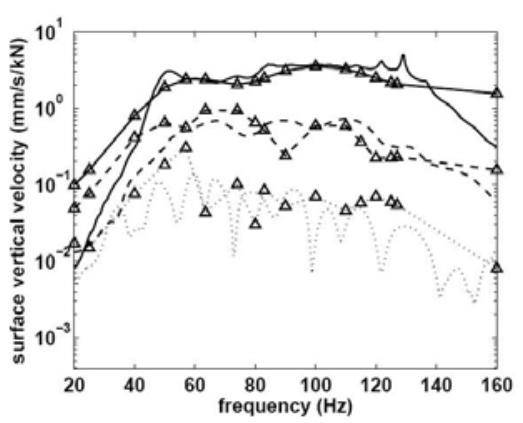

(a)

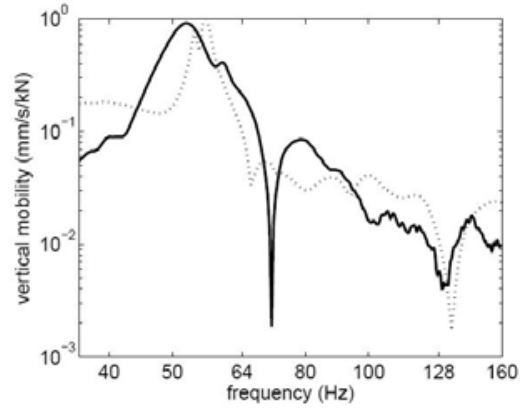

(b)

Fig. 2. (a) Experimental (solid line: $2 \mathrm{~m}$ - dashed line: $4 \mathrm{~m}$ - dotted line: $8 \mathrm{~m}$ ) and computed (triangle markers) soil admittance - (b) Experimental (solid line) and calculated (dashed line) track-soil transfer functions (mobility) at a distance $2.5 \mathrm{~m}$ from the track

\subsection{Track-Soil Behaviour}

Track characteristics are obtained using experimental investigations with hammer impacts on the rail, these being performed to measure both the ground surface response at different distances from the track and the vertical response (receptance) of the rail. In particular, the rail pad stiffness is fitted with track receptance, and bending stiffness and mass of the concrete slab are fitted with track-soil transfer functions. Each procedure is solved using a nonlinear least-squares method. Figure 2 (b) illustrates the acceptable fitted response of the soil-track model. The comparison between calculated and measured transfer functions of the track provides a validation of the complete track-soil-ground model.

\subsection{Dynamic Forces on the Rails}

In order to estimate the dynamic axle loads acting on the rails, measurements on a carrying bogie have been performed. Accelerometers have been fixed on axle boxes providing measurements of vertical vibrations close to each wheel of the bogie. Poor correlation is observed between the signals coming from the wheels of different axles whereas the coherence between the signals coming from two wheels of a same axle is very high around two frequency values (about $63 \mathrm{~Hz}$ and $125 \mathrm{~Hz}$ ), for which the accelerations are also high. These peaks probably correspond to the resonance of the axle rigid modes (translation and rotation) on the track stiffness. The total vertical force acting on the two rails by an axle is calculated by adding linearly the accelerations measured close to each wheel and by multiplying it by the total axle mass (unsuspended mass). With this method, the second peak, corresponding to the rotation of the axle, is removed from the spectrum. 


\subsection{Tramway Passage}

Validation of the complete model uses vertical vibrations of the ground surface which are considered in the frequency domain. A Fourier spectrum is performed concerning measurements, for a precise duration which corresponds to the time between two bogie passages (hence, this period depends on the tramway velocity) and the power RMS spectra $v s$. one third octave band is calculated. Calculation of the tramway passage is first implemented assuming that each axle induces a force on the rail which could be modelled as a point load. The calculated dynamics axle loads are supposed uncorrelated, according to measurements. The tramway passage is modelled assuming an initial position for the tramway, far enough from the receiver point. Next, a time increment gives another tramway position, and so on. Thus, for each tram position, vertical displacement of a considered point on the ground (receiver point) is obtained by summing each axle contribution, as power spectra. Maximum vertical velocity values are also obtained, figure 3 (a), whereas the same precise duration is used to define the average values (figure 3 (b)). A rather good agreement can be found for frequencies up to $100 \mathrm{~Hz}$. For frequencies larger than $100 \mathrm{~Hz}$, the difference between computed and experimental vertical velocities is probably due to the anti-symmetric excitation of the rails by the axle rigid rotation mode. Indeed, this excitation is not taken into account in the model since the slab rotation (torsion) is not possible. However, this phenomenon is less important when large distances from the track are considered (compared to the $2.5 \mathrm{~m}$ case described here), since Rayleigh waves propagate in a lower frequency range.

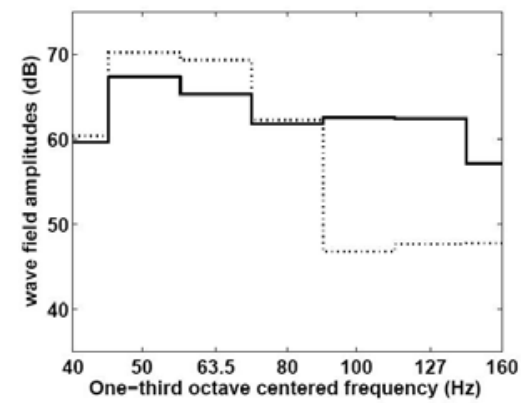

(a)

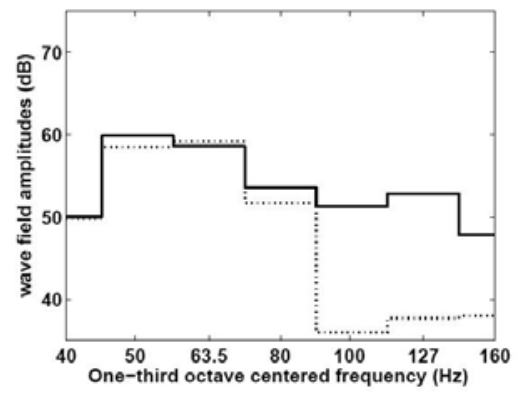

(b)

Fig. 3. Computed (dashed line) and experimental (solid line) wave field amplitudes (dB ref. $5.10^{-8} \mathrm{~m} / \mathrm{s}$ ) - Tramway passage at $50 \mathrm{~km}$ per hour - distance from the track: $2.5 \mathrm{~m}$ - (a): maximum values - (b): average values

\section{Conclusion}

In this paper, a complete model for the vehicle-track-ground is proposed to perform ground-borne vibration calculations. Vertical axle forces acting on the rail are estimated using measurements. A semi-analytical model for the track and ground is used and important parameters are fitted using measurements. Results presented here show 
that the proposed model is acceptable for a frequency range up to $100 \mathrm{~Hz}$. For frequencies above $100 \mathrm{~Hz}$, it seems that the anti-symmetric excitation of the rails cannot be neglected to predict the soil vibrations near the tracks. Current research is now focusing on the validation of the present model for other track-soil configurations (floating slab for example) and tram type (independent wheels). The calculation of dynamics axle loads from the measured unevenness of the wheel-rail surfaces is also in progress. The aim is to obtain a complete numerical model, which can be used without further measurements for the analysis and validation of new planned lines.

\section{Acknowledgements}

In addition to GeM Laboratory and INRETS, this project involves three other partners: SerdB, SEMITAN and C.D.M. The authors wish to acknowledge the ADEME Agency for its financial support, and J.P. Regoin for his great contribution concerning with the experimental investigations.

\section{References}

[1] Lombaert, G., Degrande, G., Vanhauwere, B., Vandeborght, B., François, S.: The control of ground-borne vibrations from railway traffic by means of continuous floating slabs. Journal of Sound and Vibration 297, 946-961 (2006)

[2] Sheng, X., Jones, C.J.C., Petyt, M.: Ground vibration generated by a harmonic load acting on a railway track. Journal of Sound and Vibration 225, 3-28 (1999)

[3] Jones, D.V.: The surface propagation of ground vibration. PhD thesis, University of Southampton (1987)

[4] Picoux, B., Rotinat, R., Regoin, J.P., Le Houédec, D.: Prediction and measurements of vibrations from a railway track lying on a peaty ground. Journal of Sound and Vibration 267, 575-589 (2003)

[5] Picoux, B., Le Houédec, D.: Diagnosis and prediction of vibrations from railway trains. Soil Dynamics and Earthquake Engineering 25(12), 905-921 (2005)

[6] Sheng, X., Jones, C.J.C., Thompson, D.J.: A theoretical study on the influence of the track on train-induced ground vibration. Journal of Sound and Vibration 272, 909-936 (2004)

[7] Lombaert, G., Degrande, G., Kogut, J., François, S.: The experimental validation of a numerical model for the prediction of railway induced vibrations. Journal of Sound and Vibration 297, 512-535 (2006)

[8] Cui, F., Chew, C.H.: The effectiveness of floating slab track system - part one. receptance methods. Applied Acoustics 61, 441-453 (2000)

[9] Foti, S.: Multistation methods for geotechnical characterisation using surface waves. $\mathrm{PhD}$ thesis, Politecnico di Torino, Italy (2000)

[10] Lai, C.G., Rix, G.J.: Simultaneous inversion of Rayleigh phase velocity and attenuation for near-surface site characterisation. National Science oundation and U.S. Geological Survey (1998) 